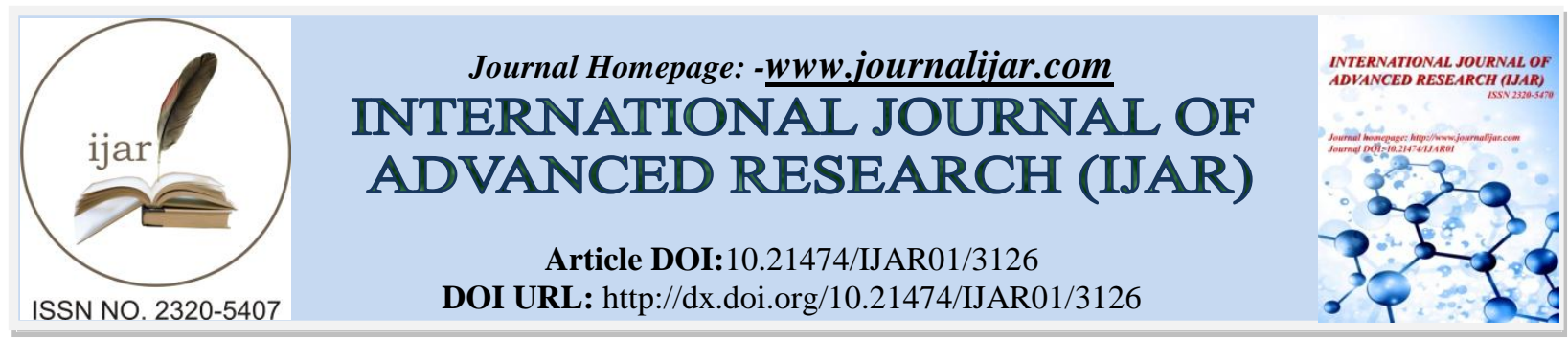

RESEARCH ARTICLE

\title{
THE IMPACT OF AMMONIUM BIFLUORIDE COMPLEX ON COLMATAGING FORMATIONS DURING THE PROCESS OFIN SITU URANIUM LEACHING.
}

\author{
M.M. Mataev ${ }^{1}$, B.R. Rakishev ${ }^{2}$ and G.S. Kenzhetaev ${ }^{1}$. \\ 1. Institute for High Technologies, Almaty, Kazakhstan. \\ 2. Kazakh National Research Technical University after K.I. Satpayev.
}

\section{Manuscript Info}

Manuscript History

Received: 09 December 2016

Final Accepted: 06 January 2017

Published: February 2017

Key words:-

colmatation, ammonium bifluoride,

sulfuric acid, $\mathrm{x}$-ray analysis.

\begin{abstract}
The causes of performance degradation geotechnical wells during ISL of uranium and detail researched the chemical sedimentations from uranium deposits. Identified effective complex of chemical reagents, which can remove sedimentations during sulfuric acid leaching of uranium. Performed laboratory research on samples of sediments and proved the concentration of the composition complex chemicals reagents. Demonstrated effective impact on permeability of the host rock during ISL of uranium.
\end{abstract}

Copy Right, IJAR, 2017,. All rights reserved.

\section{Introduction:-}

In situ leaching (ISL) of oreswithnaturalpermeabilityinvolves replacing the pore fluid in the rock layer with the solvent, which interacts with the solid and liquid phases of rocks.As a result, various physical and chemical processes occur in the bowels of the earth [1]. The long-observedoperationofgeotechnicalwellsthat were used for exploitation of uranium deposits by ISL method exhibitsthe decrease in their productivity over time. Oneofthemainproductivity loss causescan be attributed to theincreaseinhydraulicresistanceand reduced filtration in rock layers due tocolmatationformation stemming from precipitation of dissolved substances in the process solutions, or mechanical movement of particles of the ore-bearing horizon, and gas excretions.

Mechanicalcolmatationis the result of clogging of water filerorifices by sand, clay, graveland blockage of the pore channels by mechanical suspension. Sand and clay precipitate only partially, sometimes completely overlapping the filter. Clogging of filter and formation zones created by drilling fluids containing clay particles can also be attributed to a mechanical colmatation[2]. Thus, the swelling of clay mineral in an aqueous medium and alteration of the pore space of the formation structure can be observed.

Chemical, ion exchange andgascolmatation typesare caused by changes in the chemical composition of ground layer watersduring ISL as a result of impact from applicationofchemical materials. Thepresenceinwaterofdissolvedcalcium, magnesium and ironcationsand the violation of the balance of carbon dioxide leadsto the formation of sparingly soluble precipitation [3]. The allocation of carbonate sediments in the filter zone occurs intensively,however when remove the intensity of the precipitation decreases. During the reaction of leaching solutions with the host rock in the liquid phase, theaccumulation of a number of the major rockforming minerals (besides ore) occurs. Theamountandkineticsofthetransitionoftheseelementsintoproductivesolutions depends on the type of lixiviant, end concentration, redox potential, temperature, solubility of the rock-forming 
minerals and the size of the active surface of the mineral particles which in turnlargely determines the intensity of mass transfer in the solution -solid system.

The purpose of the laboratory work has been reduced to the selection of chemical reagent, capable of changing the balance of the system and transferringof insoluble in a sulfuric acid treatment compounds into a liquid phase, or convert solid colmatants into easily soluble compounds. Thetechnologythat is heavily used intheoilandgasindustrywas taken as the basis for this work. Specific acid treatment ore-bearing rocks with a special solution are used for cleaning the pore spaces, creating new solutions movements channelsand improvement of the available sizes, as well as the dissolution of clays in the near wellbore area[4].

Theanalytical work for the selection of the formulation of the most effective solution was conducted on the samples of colmatant and ore-bearing rocks. Ammoniumbifluoride (NH4HF2) and surfactants for loosening colmatant were used as additives to the sulfuric acid solution.

The ammonium bifluoride was selected due to its ability to exchange reaction with mineral acids (sulfuric, hydrochloric, nitric acid) and the formation of hydrofluoric acid.

$\mathrm{NH}_{4} \mathrm{HF}_{2}+\mathrm{HAn}=\mathrm{NH}_{4} \mathrm{An}+\mathrm{HF}$

where- $\mathrm{HAn}\left(\mathrm{H}_{2} \mathrm{SO}_{4} ; \mathrm{HCl} ; \mathrm{HNO}_{3}\right)$.

Hydrofluoric acid, resulting from the reaction, easily reacts with siliceous and aluminosilicate compounds, which are an integral part of the ore-bearing rocks and of precipitation of bridging:

$\mathrm{CaAl}_{2} \mathrm{SiO}_{8}+16 \mathrm{HF}=2 \mathrm{AlF}_{3}+2 \mathrm{SiF}_{4}+8 \mathrm{H}_{2} \mathrm{O}+\mathrm{CaF}_{2}$, $6 \mathrm{HF}+\mathrm{SiO}_{2}=\mathrm{SiF}_{4}+2 \mathrm{HF}+2 \mathrm{H}_{2} \mathrm{O}$

As a result, the dissolution of colmatant and parts ofclastic sand takes place, generally increasing the effective porosity ore array block.Thishydrofluoricacidis fullyutilizedduetothelargeamountofsilicacontainedinthesands. Results of laboratory investigations indicate the possibility of using ammonium bifluoride as an additive in a sulfuric acid solution for effective chemical treatment technology wells $[5,6]$.

Reagents included in ammonium bifluoride complex.

$500 \mathrm{ml}$ of $2 \%$ ammonium bifluoride solution is combined with $50 \mathrm{ml}$ of a $2 \%$ solution sulfoaminovoy acids (CAA) and sodium tripolyphosphate (STPP) and mixed with $100 \mathrm{ml}$ of $10 \%$ hydrochloric acid Hcl. This mixture of chemicals is conventionally denoted by the CBF. The reagents thatare used for the preparation of a fluoride complex for processing colmatant are described below:

Common inhibited hydrochloric acid $(\mathrm{HCl}) 31,27,24 \%$ concentration. Comes in tanks.Shipping and handling is carried out by means of special acid equipment. The storage is performed inrubberized containers within bund areas.

Hydrochloric acid $(\mathrm{HCl})$ - a solution of hydrogen chloride in water, emits smoke on air, forming a mist. Hydrochloric acid vapors strongly irritate the respiratory tract and mucous membranes.Prolonged exposure to hydrochloric acid vapor may cause respiratory tract catarrh, as well as the opacification of eye cornea. Skin contact causes irritation and burns.

Ammoniumbifluoride(NH4F*HF+NH4F).Its acidity in terms of hydrofluoric acid is $25 \%$, reagent density $1.27 \mathrm{~g} /$ $\mathrm{cm} 3$. Despite the fact that the use of ammonium bifluoride requires an increased consumption of hydrochloric acid to prepare a working solution(same partHCl participates in the conversion reaction of ammonium bifluoride in $\mathrm{HF}$ ), reagent is especially useful in remote areas, because it can be stored and transported by conventional methods. Ammonium bifluoride is supplied in polyethylene bags nested in four-five-layer paper bags, weighing not more than $25 \mathrm{~kg}$.Ammonium bifluoride is stored in covered warehouses, protecting it from moisture penetration. Material is a toxic agent. At higher concentrations in the air accepted limit by $(0.2 \mathrm{mg} / \mathrm{m} 3)$ may cause a violation of the central nervous system, disease bone tissue, eye, skin.

Surface active agents (surfactants) such asdisolvan, sulphonol, prevotsell, progal.Sulfonolcomesindoublekraftbags, and the other surfactants are transported and stored in steel drums. Liquid surfactants (disolvan, prevotsell) are dissolved in ethyl alcohol, thus are toxic and easily flammable. 
Sulfuric acid H2SO4 is a strong dibasic acid, exhibiting the highest degree of sulfur oxidation. Under normal conditions, the concentrated sulfuric acid is a heavy, oily,colorless and odorless liquid with sour, "copper" taste.Sulfuric acid can also be represented as a mixture with water, or with sulfur trioxide SO3. Sulphuric acid and oleum are highly corrosive substances. By inhalation of these substances, they cause shortness of breath, cough.

Hydrofluoric acid (HF) $40 \%$ has concentration density of 1,15g / cm3. Transportation and storage of hydrofluoric acid must be carried out in plastic containers. Hydrofluoric acid - hydrogen fluoride solution in water, emits smoke in the air, forming mist. Hydrofluoric acid vapors strongly irritate the respiratory tract and mucous membranes, prolonged exposure to hydrofluoric acid vapor may cause srespiratory tract catarrh, blurred cornea of the eye. Skin contact can causes severe burns[7].

Laboratory experiments have shown that the most effective colmatatingmixturecomposition is a solution of $10 \%$ sulfuric acid or hydrochloric acid with the addition of ammonium bifluoride $2-2.5 \%$ by weight.

Colmatant phase composition was monitored by X-ray diffraction analysis, which wascarried out on the X-ray diffractometerX'Pert MPD PRO (PANalytical). Shooting conditions: $\mathrm{CuK}_{\mathrm{a}}$ - radiation, $\mathrm{Ni}$ - filter, $U=30 \mathrm{\kappa B}, I=10$ $\mathrm{MA}$, the rotational speed of $1000 \mathrm{pulses} / \mathrm{s}$, the time constant $\tau=5 \mathrm{~s}, 2 \theta=10^{\circ}-90^{\circ}$. Intensities ofdiffraction maxima were evaluated on a 100 point scale as a percentage of the highest line.The processing of experimental data and the interplanarspacings were performed according to the Wulff- Bragg formula. Phase analysis of the chemical composition of bridging materials were determined according to X-ray crystallographic data of the international community.

JEOL 6510EX electron microscope was used to acquire images of the surface sediments with high (up to $0.4 \mathrm{~nm}$ ) spatial resolution, as well as for information about the composition, structure and other properties of the near-surface layers of the micro-diffrations. The method is based on the principle of interaction of the electron beam with the object under study.

The physico-chemical analysis results discussion.

The goal of the study was to evaluate the dissolving ability of different chemicals of varying sediment concentrations in controlled laboratory settings. Then, select the optimal chemical composition based on the analysis results.

For the pilot study the sedimentation from the interior surface of the submersible pumps from four fields located in the Syrdarya uranium ore province.Dried precipitates №1 is a dust-like mixture with the presence of large homogeneous formations and sand particles.Dried precipitates №2 is a white powder with beige spots.

Forphysical and chemical analysis purposes the samples of colmatant were ground in an agate mortar to a powder. The powder was examined by x-ray analysis. Stable reflection X-ray radiograph colmatant №1 (Fig. 1) shows a high crystallization sediment-chemical compounds. Analysis of the values of interplanar distances confirms the existence of feldspar particles, silica-alumina complex ferrous and plaster. Amorphous state is noticeable due to weak reflection of X-rays. 


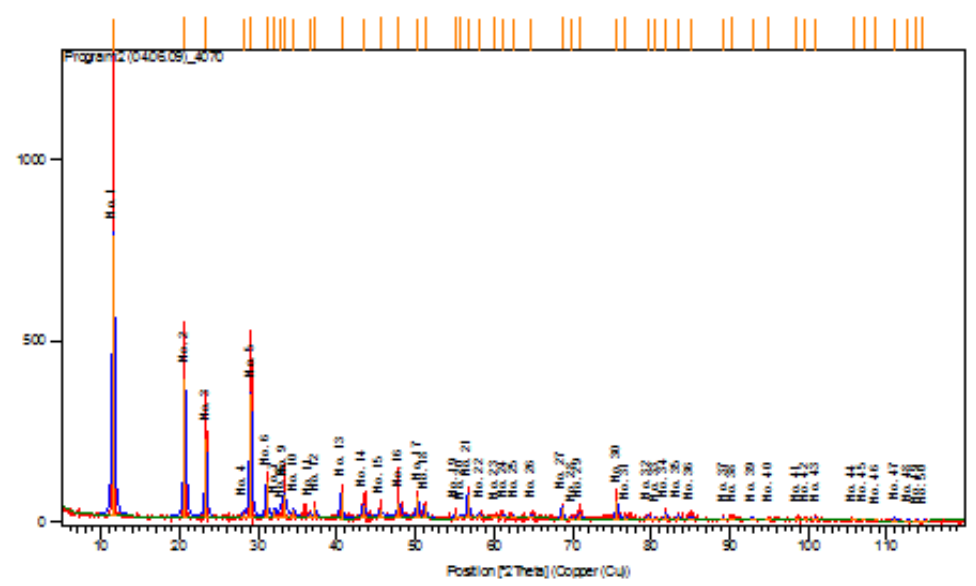

Figure 1:- The XRD pattern colmatant to chemical treatment.

The X-ray diffraction of colmatant in Table 1 shows the quantitative chemical and mineralogical composition of colmatagingobjects. The data in Table 1 show that colmatant is majorly based (about 70\%) on a chemical compound $(\mathrm{CaSO} 4 \cdot 2 \mathrm{H} 2 \mathrm{O})$, mineral - gypsum. The remainder of thecolmatantcomprises fromgibshit rock-forming minerals, anorthite and amphibole $(3 \%, 20 \%, 7 \%$, respectively).

Table 1:- Chemical composition colmatant №1

\begin{tabular}{|l|l|l|l|c|}
\hline & Reference code & $\begin{array}{l}\text { The name of } \\
\text { composition }\end{array}$ & Chemical formula & Content [\%] \\
\hline & $00-036-0432$ & Gypsum & $\mathrm{CaSO}_{4} \cdot 2 \mathrm{H}_{2} \mathrm{O}$ & 70 \\
\hline & $01-075-1690$ & Gibshit & $\mathrm{Ca}_{3} \mathrm{Al}_{2}\left(\mathrm{Si} \mathrm{O}_{4}\right)_{1.53}(\mathrm{OH})_{5.88}$ & 3 \\
\hline $01-087-1616$ & Anorthite & $\mathrm{Ca}\left(\mathrm{Al}_{2} \mathrm{Si}_{2} \mathrm{O}_{8}\right)$ & 20 \\
\hline & $01-081-1135$ & Amphibole & $\left(\mathrm{Ca}_{5.76} \mathrm{Mg}_{0.24}\right)\left(\mathrm{Al}_{4.44} \mathrm{Fe}_{0.48} \mathrm{Si}_{2.08} \mathrm{O}_{16}\right) \mathrm{Cl}_{2.76}$ & 7 \\
\hline
\end{tabular}

These results prove satisfactory matching to published data of interplanarspacings with the experimental

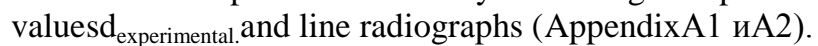

Drip method was used to determine dissolving properties of ammonium bifluoride and mineral acids in processing precipitations. The №1 sample was treated with the composition complex of ammonium bifluoride, №2 sample was processed by solvent composition of $12 \%$ hydrochloric acid, №3 sample was subjected to the treatment of $12 \%$ sulfuric acid. During processing a marked penetration of fluids precipitate to varying degrees with a slight change in the amount and color of colmatagingobject. The dryingof processed materials is held at room temperature under a fume hood at atmospheric conditions. After drying, precipitateswere triturated in an agate mortar to study phase composition of treated samples. The results of X-ray analysis of the sample №1 (Figure 2) showed the polycrystalline nature of the crystallization of the samples, as well as changes in the crystal chemical and mineralogical composition compared to the original colmatant. 


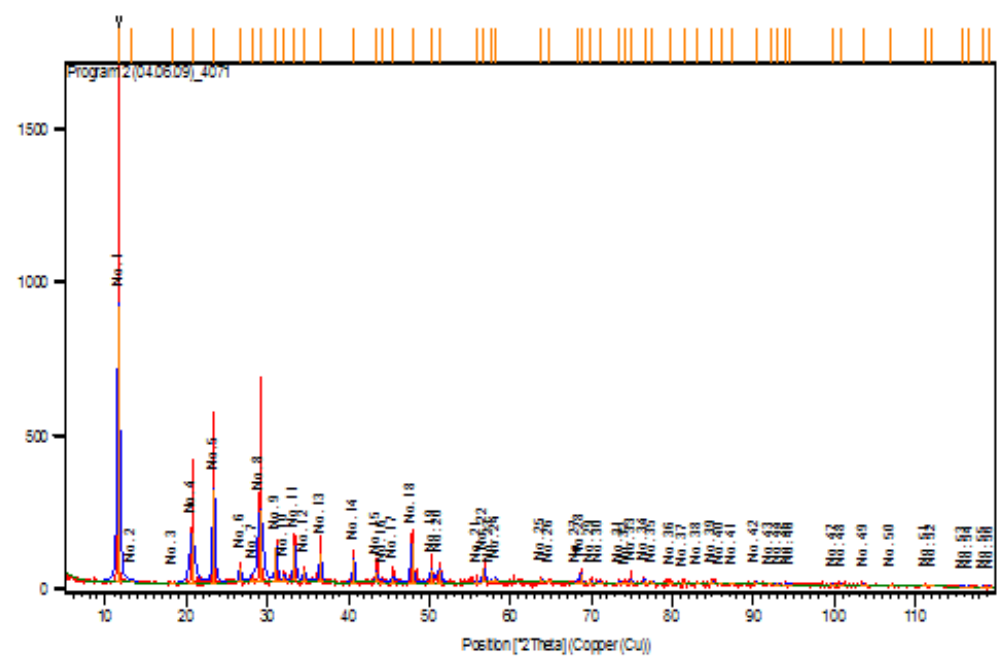

Figure 2:-colmatant №1 diffractogram after chemical treatment.

Characteristics of spectral reflections of the X-ray radiograph (Figure 2) remainsimilar in their colmatant diffraction patterns to those before the processing (Fig. 1). This is explained by the fact that all the minerals in the composition of colmatant is of isistructuralcrysallizationtype. Table 2 shows the quantitative phase and mineral composition data of colmatants after chemical processing with ammonium bifluoride.

Table 2:- Chemical composition colmatant after chemical treatment.

\begin{tabular}{|c|c|c|c|}
\hline Reference code & $\begin{array}{l}\text { The name of } \\
\text { composition }\end{array}$ & Chemical formula & $\begin{array}{l}\text { Content } \\
{[\%]}\end{array}$ \\
\hline $01-085-1569$ & Granite & $\mathrm{Ca}_{2.83}\left(\mathrm{Al}_{5.66} \mathrm{Si}_{10.34} \mathrm{O}_{32}\right)\left(\mathrm{H}_{2} \mathrm{O}\right)_{7.1}$ & 13 \\
\hline 01-073-2041 & Gelit & $\mathrm{Ca}_{2}\left(\mathrm{Al}(\mathrm{AlSi}) \mathrm{O}_{7}\right)$ & 4 \\
\hline 01-074-1559 & Andradite & $\left(\mathrm{Ca}_{2.97} \mathrm{Mg} \cdot{ }_{\cdot 02} \mathrm{Mn}_{.01}\right)\left(\mathrm{Fe}_{1.99} \mathrm{Al}_{.01}\right)\left(\mathrm{Si}_{4}\right)_{3}$ & 2 \\
\hline $01-072-0467$ & Orthosilicate & $\mathrm{Ca} \mathrm{Al}_{2} \mathrm{Si}_{2} \mathrm{O}_{8}\left(\mathrm{H}_{2} \mathrm{O}\right)_{4}$ & 38 \\
\hline $01-089-8754$ & Grossular & $\mathrm{Ca}\left(\mathrm{Al}_{4} \mathrm{Si}_{2} \mathrm{O}_{11}\right)$ & 1 \\
\hline $01-072-2375$ & Epidote & $\mathrm{Ca}_{2} \mathrm{Al}_{2} \mathrm{Fe} \mathrm{Si}_{3} \mathrm{O}_{12}(\mathrm{OH})$ & 5 \\
\hline 01-089-7304 & Pirop & $\left(\mathrm{Mg}_{0.92} \mathrm{Fe}_{0.05} \mathrm{Ca}_{0.03}\right)_{3} \mathrm{Al}_{2}\left(\mathrm{Si} \mathrm{O}_{4}\right)_{3}$ & 5 \\
\hline 00-041-1479 & Clinozoisite & $\mathrm{Ca}_{2} \mathrm{Al}_{3}\left(\mathrm{Si} \mathrm{O}_{4}\right)\left(\mathrm{Si}_{2} \mathrm{O}_{7}\right) \mathrm{O}(\mathrm{OH})$ & 32 \\
\hline
\end{tabular}

TheresultsofX-rayanalysisofthesample №1 showedthe dissolution ofcolmatagingchemicalcompoundof gypsumaccording to thechemicalreaction:

$$
\mathrm{CaSO}_{4} \cdot 2 \mathrm{H}_{2} \mathrm{O}+2 \mathrm{HF}=\mathrm{CaF}_{2}+\mathrm{H}_{2} \mathrm{SO}_{4}+2 \mathrm{H}_{2} \mathrm{O}
$$

The reaction products are strong electrolytes ( $\mathrm{CaF} 2, \mathrm{H} 2 \mathrm{SO} 4)$ which dissociate into ionsin aqueous solution. Calcium cationsareinvolved in the formation the minerals of different composition (Table 2), showing that increase in the amounts of calcium containing minerals. Solutions of the fluoride ions react with siliceous and aluminosilicate compounds. Sulfuric acid acts as a leaching agent.

Study of the surface colmatantusing scanning electron microscope (Figure 3) shows the frame structure of the mechanism, with a complex association of groups of atoms and molecules, as well as the lack of gaps between the lateral planes, proving close-packed nature of the crystallization colmataging chemical compounds. 


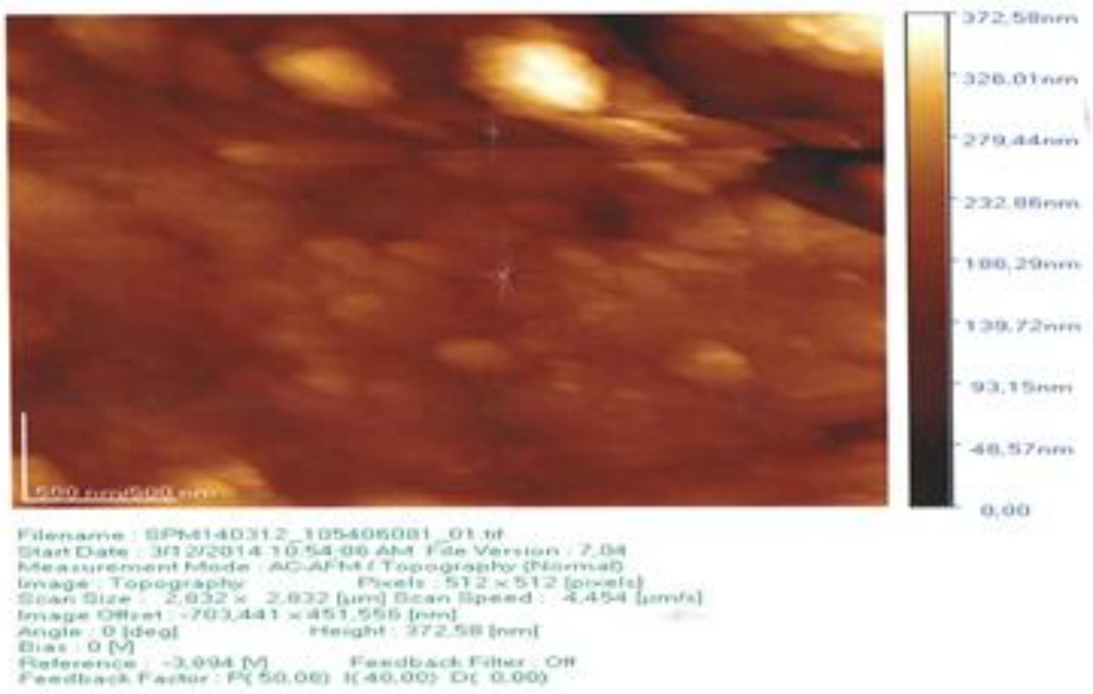

Figure 3:- Image colmatant surface before processing.

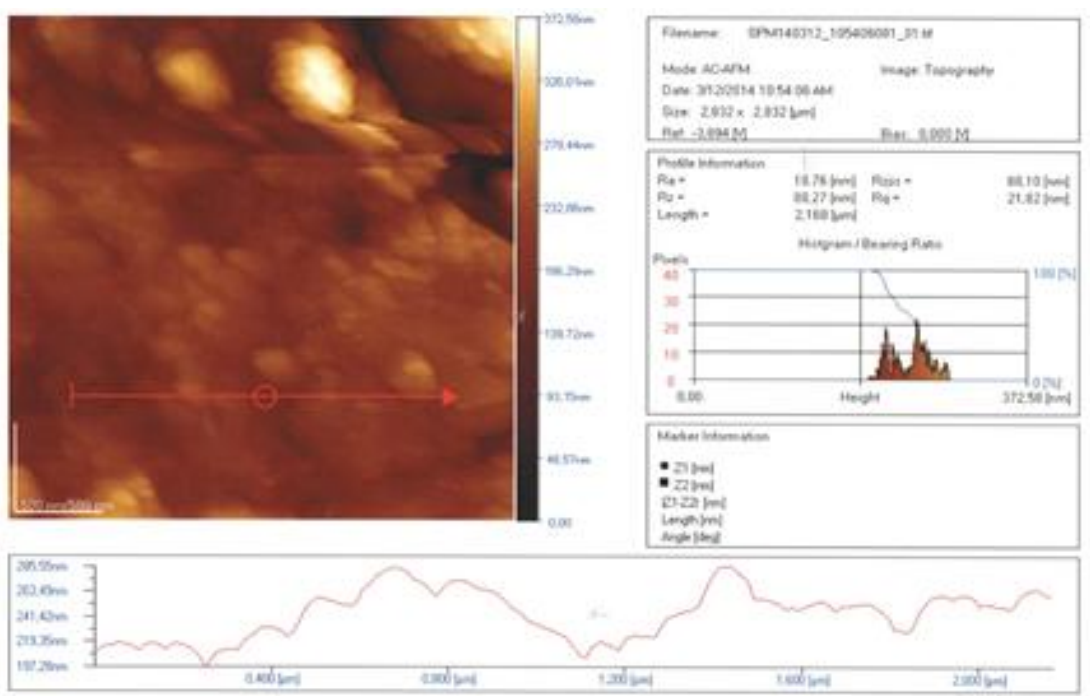

Figure 4:- Topography of the colmatant surface prior to treatment.

Figure 4 shows a picture of the surface microdiffractioncolmatagingobjects. The profile of the histogram shows that the surface is formed by polymerization of silicate to the skeletal structure, which represents an infinite body-tallies framework of $\mathrm{SiO} 4$ tetrahedrons and $\mathrm{AlO} 4$, in the cavities of which there are other ions, as a result of the drying process, they can turn into a clay and various kinds of silica. Structure without rupture, solid, formation of voids and cracks were not observed.

Post chemical processing(complex of ammonium bifluoride, $12 \%$ hydrochloric acid and sulfuric acid)drying and preparation ofcolmatant samples was performed at room temperature for 24 hours. The results of electron diffraction studies (Figure 5) showed a change in the morphology of the surface of the colmatant.As the result,new chemical formations are being composed within colmataing substance. Chemical formations can be described as smears, with discontinuous streaks and cracks. 


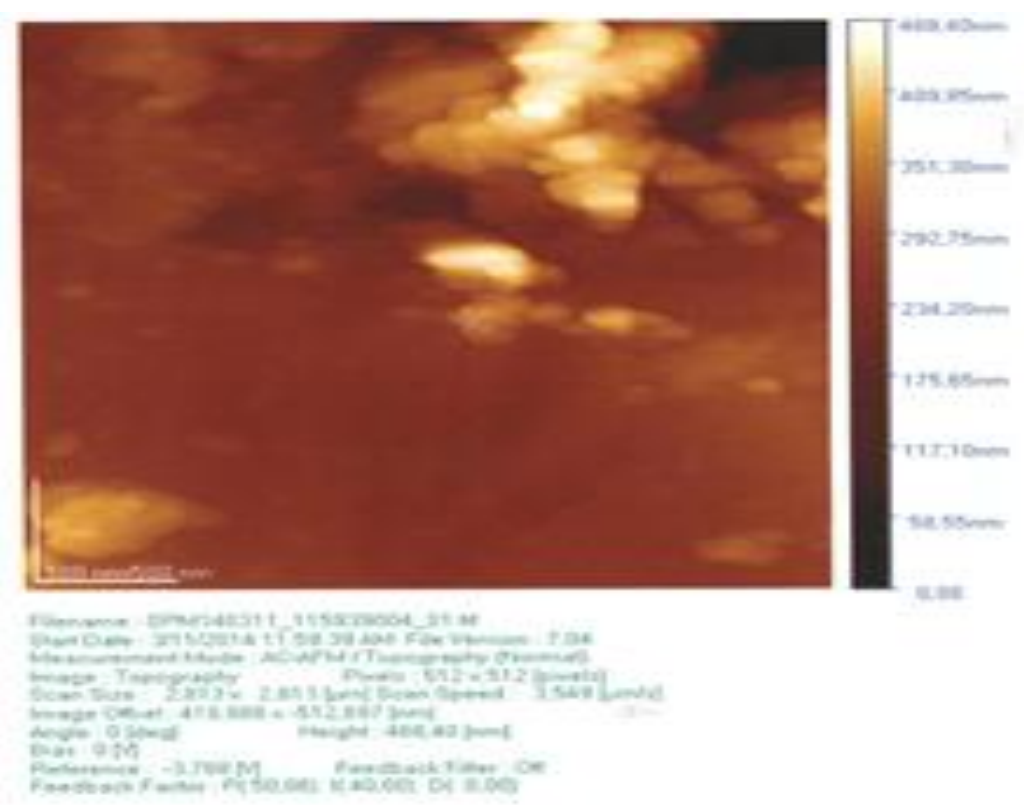

Figure 5:- Image of the colmatant surface after chemical treatment.

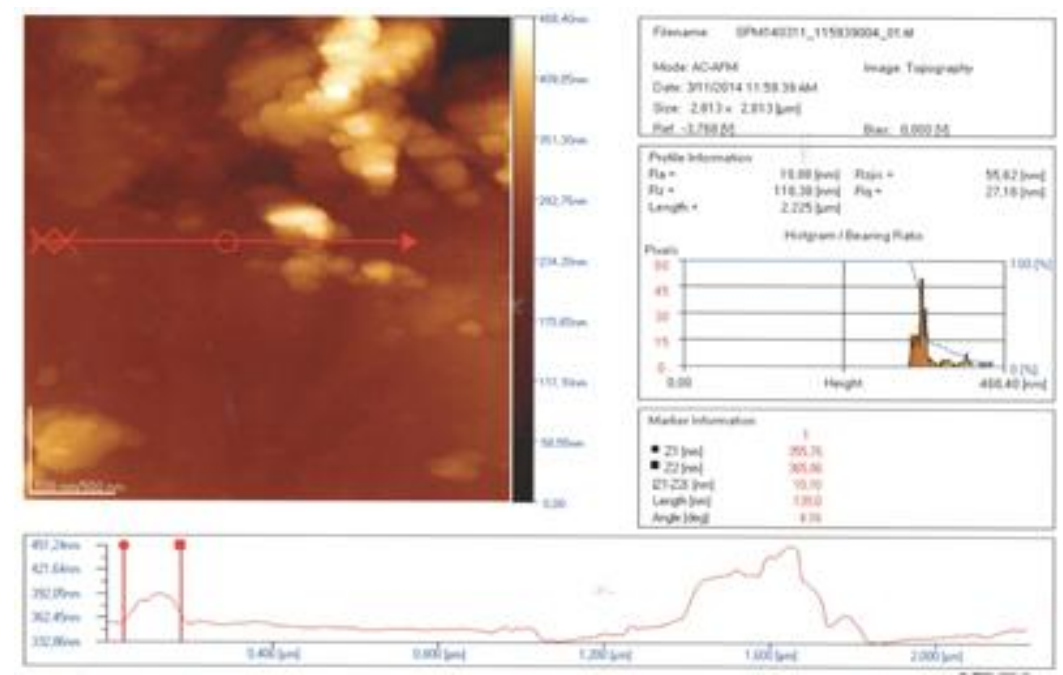

Figure 6:- Colmatant surface topography after chemical treatment.

Microdiffractionof colmatant surface after chemical treatment is shown on Figure 6. The surface histogram profile shows a surface discontinuity in a region varying from $200 \mathrm{~nm}$ to $300 \mathrm{~nm}$, which proves the structural transformation of colmatant, as well aschanges in the chemical composition of the sediment-systems.

Investigationandanalysisoflaboratoryexperimentsshows that chemicals differently affect the colmatagingsediments, depending on the composition and concentration.However, the ammonium bifluoride's effect isstrong. According to the electrondiffractionsthecomplex of ammonium bifluorideisthemostworkable, effectively dissolving the gypsum and producing the maximum depth of a deepening in the sample by destroying the crystal structure colmatant.Thus, the ammonium bifluoride shows better characteristics compared to the solution of $12 \%$ hydrochloric or sulfuric acid.

The dissolving capabilities of the tested solutions are directly depended on the chemical composition of colmatingformations and quantitative characteristics of sediment-rock. Its main component, gypsum, is a product of the chemical process of sulfuric acid leaching, its content is $70 \%$ by weight of thecolmatant. Laboratory studies have shown the effectiveness of ammonium bifluoride usageas an additive in sulfuric acid solutions that are effective for carrying out chemical treatments of colmatant. The complex of ammonium bifluoride - $10 \%$ solution of sulfuric acid or hydrochloric acid with the addition ammonium bifluoride $2-2.5 \%$ by weight was developed.X-ray 
diffraction and electron analysis revealed the complete dissolution of the main colmatant element - gypsum. As the result of chemical processes new formations were observed.Changes were found in the surface morphology and in the formation of voids and cracks of colmatant. To sum up, theammonium bifluoride complex can be successfully used as a chemical reagent for treating geotechnological wells during their regeneration.

\section{Bibliography:-}

1. Mamilov VA Uranium mining by in-situ leaching. Moscow: Atomizdat $1980-248 \mathrm{p}$.

2. Romanenko VA, Volnitskaya EM Restoration performance of water wells. Leningrad: "Nedra" 1986-112 p.

3. Ivashechkin VV, Cervical AM, KondratovichAN Regeneration of wells and water supply systems, pressure filters Minsk: Belarusian National Technical University, 2008 - 277 p.

4. Ivanov SI The intensification of the flow of oil and gas to the wells. Moscow: Nedra, 2006 - $565 \mathrm{p}$.

5. Blazevic VA, VG Umetbaev Directory master workover. Moscow: "Nedra" 1985 - 208 p.

6. Mataev MM, Kenzhetaev JS Selection of effective methods of repair and restoration work in underground uranium leaching// Advances in Current Natural Sciences №1, 2015 - 1001 - 1004 p.

7. Bashkatov AD Advanced technologies well construction. M.: "Core-business centers" in $2003-554$ p. 